\title{
Frequency of Patients Presenting with Recurrent Aphthous Stomatitis: A Pilot Study
}

\author{
ShijithMalayil ${ }^{1}$, Jincy Thomas ${ }^{2}$, P. Rani $\mathrm{Mol}^{3}$, D.A. Vineet ${ }^{4}$, Sunila Thomas ${ }^{5}$, \\ V.Vivek ${ }^{6}$ \\ ${ }^{1}$ (Post graduate student, Department of oral medicine and radiology, PMS College of Dental science \& \\ Research, India) \\ ${ }_{2}^{2}$ (Senior Lecturer, Department of oral medicine and radiology, PMS College of Dental science \& Research, \\ India) \\ ${ }^{3}$ (Senior Lecturer, Department of oral medicine and radiology, PMS College of Dental science \& Research, \\ India) \\ ${ }^{4}$ (Reader, Department of oral medicine and radiology, PMS College of Dental science \& Research, India) \\ ${ }^{5}$ (Professor, Department of oral medicine and radiology, PMS College of Dental science \& Research, India) \\ ${ }^{6}$ (Professor \& Head of Department, Department of oral medicine and radiology, PMS College of Dental \\ science \& Research, India)
}

\begin{abstract}
Recurrent Aphthous Stomatitis (RAS) is considered as the most common ulcerative condition of the oral mucosa. A study was conducted to evaluate the prevalence of RAS in a rural population from South Kerala, India. A total of 10518 patients attending PMS College of Dental Science and Research over a period of one year were examined for RAS according to age, gender, and site of lesion. RAS was identified in $0.48 \%$ of patients with 1.3:1 female to male ratio and lower labial mucosa showing maximum incidence among patients attending outpatient department of dental college located in a rural area of South Kerala. RAS is a condition that commonly affects young adults. Even though not life threatening it can significantly affect the health related quality of life of an individual. In our study population the prevalence of RAS was $0.48 \%$ with female predilection. Lower labial mucosa was found to be most affected site followed by tongue.
\end{abstract}

Key words: Recurrent Aphthous Stomatitis, Prevalence, Pilot study, South Kerala

\section{Introduction}

RAS is considered as the most common ulcerative condition of the oral mucosa [1,2]. Aphthous ulcers are classified on the basis of ulcer size in to major, minor, and herpetiform. Minor aphthous ulcers are small (less than one $\mathrm{cm}$ in diameter), well defined, shallow, and heal within 2 weeks without scars (Fig. 1). Major ulcers are bigger, deeper, and take up to six weeks to heal leaving a scar behind (Fig. 2). Herpetiform ulceration is also characterized by small $(3-6 \mathrm{~mm})$, shallow ulcers which takes weeks to heal, but with many numerous ulcers at once [3]. Occurrences begin at about 5 years of age and continues throughout life with a peak onset between 10 and 19 years [4]. The etiology of RAS is not understood. RAS may be precipitated by, or with local trauma, stress, food hypersensitivity, hormonal changes, microorganisms, vitamin and trace element deficiencies. Systemic conditions including genetic predisposition, immune deregulation, and family history might play a role in recurrent aphthous ulceration in some patients [3].Prevalence of aphthous ulcers were reported to vary from $5-66 \%$ among different nations [5, 6]. The prevalence of RAS was $28.2 \%$ in Iraq [7]. Even though not life threatening it can significantly affect the health related quality of life of an individual.In this article, a dental college based pilot study was carried out using already existing data collected during a period of one year. We attempt to report the frequency of occurrence of RAS in the patients of the population visiting PMS college of dental science and research, Trivandrum, Kerala.

\section{Materials \& Methods}

Ethical committee clearance for this study obtained from institutional ethical committee. A total of 10518 patients from Vattappara, a rural area near Trivandrum who attended the outpatient department of PMS college of dental science and research over a period of one year from March 2012 to February 2013 were examined for clinical evidence of RAS. The data on age, gender, and site of lesion were recorded. RAS was diagnosed depending on clinical history and examination.

\section{Results}

Out of the 10518 patients examined, RAS was identified in 51 patients. Out of 51 patients with RAS, $22(43 \%)$ were males and $29(56 \%)$ were females (Fig. 3). The female to male ratio was 1.3: 1. Overall 
prevalence of RAS was found to be $0.48 \%$. Majority of our patients with RAS (94\%) presented with minor aphthae (Fig. 4). Patients who were in their $2^{\text {nd }}$ to $5^{\text {th }}$ decade showed higher prevalence of the lesion (Fig. 5). Most common site was labial mucosa followed by tongue and buccal mucosa. Patients also presented with lesions on multiple sites.

\section{Discussion}

RAS is a common condition affecting the oral cavity. Prevalence of RAS from this study was estimated as $0.48 \%$. In a study conducted in Malaysia where 1167 subjects were examined for RAS, the reported prevalence rate was $0.5 \%$ [8].A two year study conducted in dental patients of Tabriz, Norwest Iran between May 2002 and October 2004 reported a prevalence of $0.3 \%$ [9].

Most studies showed that RAS has predilection among women. The observations in our study showed that females were more affected (56\%) than males. A study conducted in 10291 patients in the city of Tehran, Iran showed a female predilection for RAS that may be attributed to hormonal changes [6]. Women with RAS often present with cyclical oral ulcerations related to the luteal phase of the menstrual cycle [10, 11]. Reduction in the incidence of RAS during pregnancy may be an indicator of its association with progesterone levels [12]. However data from the $3^{\text {rd }}$ national health \& nutrition examination survey analyzed in Sudaan reported that incidence of RAS was greater in men [13].

In our study common site of RAS was on labial mucosa followed by tongue and buccal mucosa. According to a questionnaire related study conducted in 684 dental patients who attended Jordan University of science and technology's dental teaching centre for examination and treatment reported 55\% of RAS were located at lips and buccal mucosa [3]. A cross sectional survey was carried out among 1100 patients in Sulaimani city, Iraq reported that lips and buccal mucosa were the commonest site [7].

RAS was most common in age group of 20-29 years, reported in a study conducted among 1100 patients in Sulaimani city, Iraq [7]. Data analysis from the $3^{\text {rd }}$ National Health \& Nutrition Examination survey, 1988-1994 reported adults younger than 40 years of age had almost twice the prevalence of those older than 40 years [14]. We observed that RAS was more in the $2^{\text {nd }}-5^{\text {th }}$ decade.

Among the 3 cases of major aphthous ulcer reported, one was presented along with minor aphthous ulcer. All the patients with major aphthous were males and one was at tongue and two were at labial mucosa. Majority of our patients with RAS (94\%) presented with minor aphthae which is in accordance with previous studies [11].

\section{FIGURES AND TABLE}

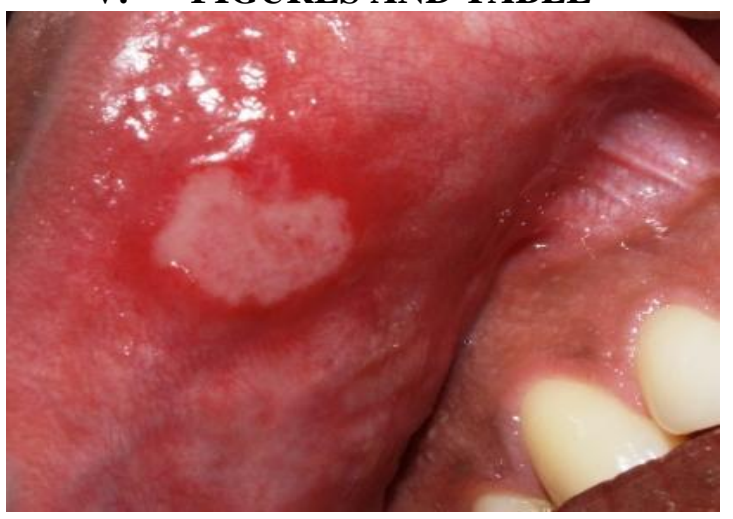

Fig. 1 Minor aphthous ulcer

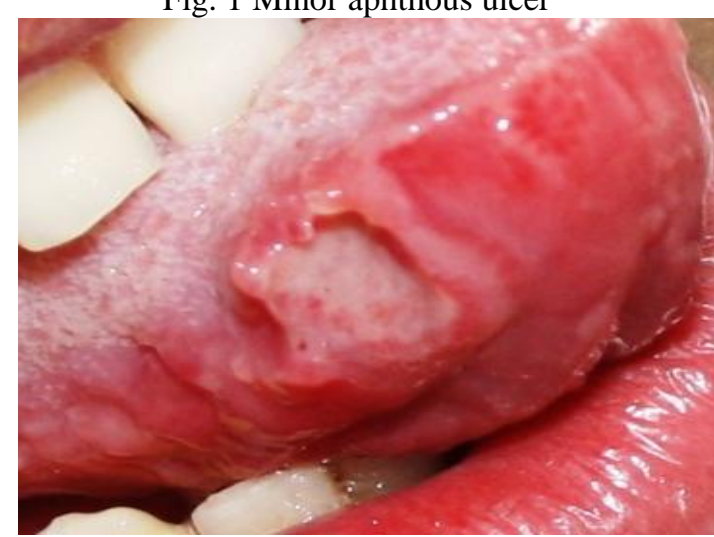

Fig. 2 Major aphthous ulcer 


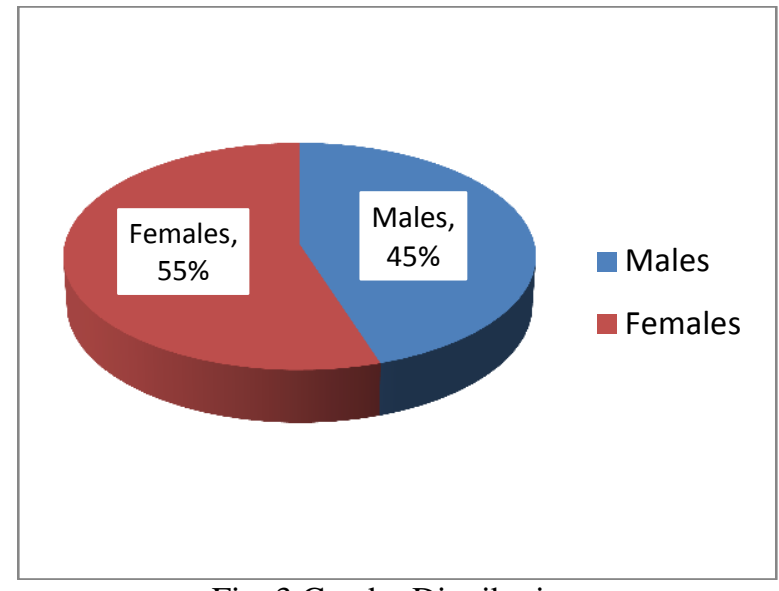

Fig. 3 Gender Distribution

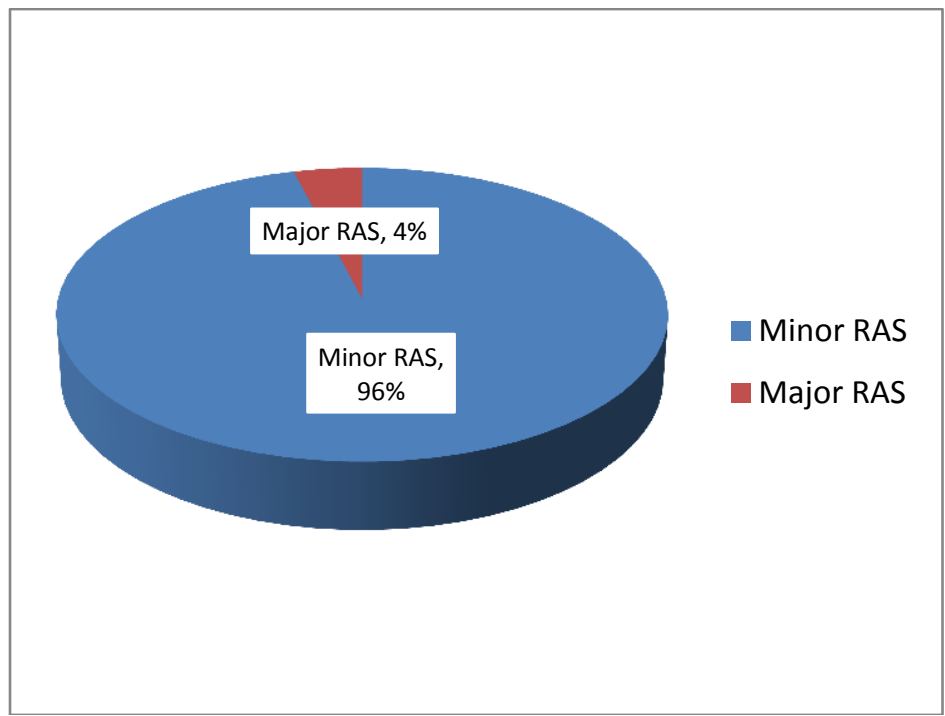

Fig. 4 Type Distribution of RAS

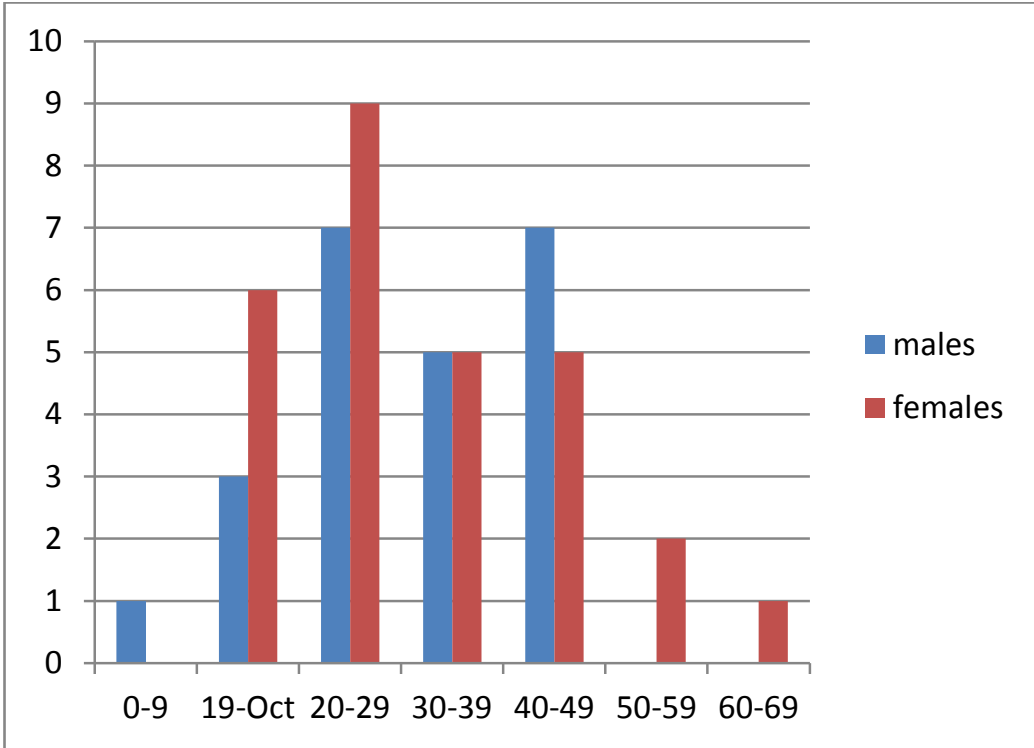

Fig. 5 Age Group Distribution of RAS in males and females 


\begin{tabular}{|l|l|l|}
\hline \multicolumn{3}{|c|}{ Table 1: Site distribution } \\
\hline Site & Number & Percentage \\
\hline Tongue & 24 & 46 \\
\hline Labial mucosa & 18 & 35 \\
\hline Buccal mucosa & 8 & 16 \\
\hline Soft palate & 1 & 3 \\
\hline
\end{tabular}

\section{Conclusion}

Understanding the prevalence and distribution of recurrent aphthous ulceration among rural area in South Kerala will give an indication about the proportion of people who suffer the condition and who need care. In our study the prevalence of RAS was $0.48 \%$ with female predilection. Labial mucosa was found to be the most affected site followed by tongue. RAS is commonly affecting young adults. Knowledge about the prevalence of RAS might help dental practitioner in reaching proper diagnosis of the ulcer affecting oral cavities and in providing information to patient to enhance their awareness about the condition.

\section{References}

[1]. Witman PM, Rogers RS: Pediatric oral medicine. DermatolClin21(1), 2003, 157-170.

[2]. Scully C, Porter S: Oral mucosal disease: Recurrent aphthous stomatitis. Br J Oral MaxillofacSurg 49(2), 2008, 198-206.

[3]. Safadi RA. Prevalence of recurrent aphthous ulceration in Jordanian dental patients. BMC Oral Health 9(1), $2009,31$.

[4]. Vivek V, Nair BJ. Recurrent aphthous stomatitis: Current concepts in diagnosis and management. Journal of Indian Academy of Oral Medicine and Radiology 23(3),2011, 232-236.

[5]. Porter SR, Scully C, Pedersen A: Recurrent aphthous stomatitis .Crit Rev Oral Biol Med 9(1), 1998, $306-321$.

[6]. Davatchi F, Tehrani-Banihashemi A , Jamshidi AR, Chams-DavatchiC,Gholami J, Moradi M, Akshlami M, Forouzanfar HM, Barghami M ,Noorolahzadeh E, Samadi F, Aliloo HM, Ghaznavi K, Soroosh M, Khabezi A, Sarari HA, Sharif KS , Karimifar M, Salessi M, Manesh EK, Nadji A, Shahram F. The prevalence of oral aphthosis in a normal population in Iran: a WHO-ILAR CORPCORD study. Arch Iran Med 11(1), 2008, 207-9.

[7]. Abdullah JM. Prevalence of aphthous ulceration experience in patients attending pyramird dental specialty in sulaimani city. $J$ ClinExp Dent 5(2), 2013, 89-94.

[8]. ZAIN, R.B .Oral recurrent aphthous ulcers/stomatitis: Prevalence in Malasysia and an epidemiological update. Journal of oral science 42(2), 2000, 15-19.

[9]. 9.Sina M, Toorchi M, Vosoughhosseini S, Zenouz AT, Mehdipour M. two -year prevalence of minor aphthae in Tabriz, Northwest Iran. J Dent Res Dent Clin Dent Prospect 3(2),2009, 17-9.

[10]. Field EA, Allan RB. Review article: oral ulceration- aetiopathogenesis, clinical diagnosis and management in the gastrointestinal clinic. Aliment PharmacolTher 18 (1), 2003, 949-62.

[11]. Balan U, Gonsalves N, Jose M, Girish KL. Symptomatic changes of oral mucosa during normal hormonal turnover in healthy young menstruating woman. J Contemp Dent Pract 13(1), 2012, 178-81.

[12]. Scully C, Gorsky M, Lozada- Nur F. The diagnosis and management of recurrent aphthous stomatitis: a consensus approach. $J$ Am Dent Assoc 134(1),2003, 200-205.

[13]. Chattopadhyaya A, chatterjee S. Risk indicators for recurrent aphthous ulcer among in the US. Community dentistry and epidemiology 35(2), 2007, 152-159.

[14]. Rivera-Hidalgo F, Shulman JD, Beach MM. The association of tobacco and other factors with recurrent aphthous stomatitis in an US adult population. Oral Dis 10(2),2004, 335-45. 